\title{
The Mediating Effects of Parenting Stress, Child's Temperament and Emotional Regulation in the Relationship Between Mother's Parenting Sensitivity and Child's School Readiness
}

\author{
Mi Kyung Shim ${ }^{1}$, Ju Young Woo ${ }^{2}$ \\ Professor, Department of Early Childhood Education, Inje University, Kimhae, Korea ${ }^{1}$ \\ Associate Professor, Department of Psychological Rehabilitation, Korea Nazarene University, Cheonan, Korea ${ }^{2}$ \\ 어머니의 양육민감성과 유아의 학교준비도 간의 관계에서 양육스트레스, \\ 유아의 기질 및 정서조절능력의 매개효과 \\ 심미경 ${ }^{1}$ 우주영 \\ 인제대학교 유아교육과 교수 ${ }^{1}$ 나사렛대학교 심리재활학과 부교수 ${ }^{2}$
}

Objectives: The study was conducted to verify the mediating effects of parenting stress, child's temperament, and emotional regulation on the relationship between mothers' parenting sensitivity and preschoolers' school readiness.

Methods: Questionnaires were distributed among a total of 400 parents and 286 teachers, finally each of 271 were analyzed, from 12 institutes of early childhood education in $\mathrm{K}$ area. The model was tested using the SPSS and AMOS programs.

Results: First, mothers' parenting sensitivity had a direct impact on parenting stress, the child's temperament, and emotional regulation. Second, the mother's parenting stress had a direct effect on child's emotional regulation, but child's temperament had no effect on it. Third, parenting sensitivity partially mediated the effect of parenting stress, and parenting stress had a serial multiple mediating effect on school readiness, through mediating child's emotional regulation. Parenting sensibility also affected school readiness through mediating child's emotional regulation. Fourth, parenting stress influenced school readiness by fully mediating child's emotional regulation. However, child's temperament did not affect emotional regulation, and had no mediating effect on school readiness through emotional regulation.

Conclusion: The higher the mother's parenting sensitivity, the lower the rate at which parenting stress increases. This, then, continuously led to the increase of child's emotional regulation. This, in turn, had a more positive impact on school readiness. In addition, this study found that mothers' parenting sensitivities enhance the child's emotional regulation and improves their school readiness.

Keywords: parenting sensitivity, school readiness, parenting stress, temperament, emotional regulation

\section{Introduction}

학령초기의 학교적응은 그 이후의 적응에 영향을 미치는 중요

Corresponding Author: Ju Young Woo, Associate Professor, Department of Psychological Rehabilitation, Korea Nazarene University, Wolbong-ro 48, Ssangyong-dong, Seobuk-gu, Cheonan-si, Chungcheongnam-do, Korea E-mail:wjy0207@hanmail.net
한 요소로 강조되고 있다. 취학 전 아동에게 초등학교로의 전 이는 유아교육기관에 비해 보다 정형화된 새로운 사회적 체 계에 적응해야 하는 전환기로서, 이에 대한 발달적 준비가 필

(C)The Korean Association of Child Studies

This is an Open Access article distributed under the terms of the Creative Commons Attribution Non-Commercial License (http:// creativecommons.org/licenses/by-nc/4.0) which permits unrestricted noncommercial use, distribution, and reproduction in any medium, provided the original work is properly cited. 
요하다. 이 시기에 요구되는 총제적인 발달 역량을 학교준비 도(school readiness)로 개념화하고 있다(Y. Cho, 2018). 학교준 비도는 학교생활에 대한 적응 및 학업태도와 수행을 예측함 과 동시에 현재의 발달적 양상이 적절한지도 반영한다. 이러 한 학교준비도에 대한 발달적 관점은 예전에는 읽기, 쓰기, 셈 하기 등 학습적인 요인과 관련된 개인적 성숙 수준에 초점을 두었으나 최근에는 아동과 환경 간의 양방향성에 초점을 두 고 있다(Murphey \& Burns, 2002). 즉, 학교준비도를 아동 자신 과 아동의 발달을 최적화하는데 필요한 환경적, 문화적 경험 들 간의 상호작용에 의한 결과적 산물로 이해하며, 학업수행 뿐 아니라 학교생활 전반에 걸친 사회적 적응 영역을 포괄하 는 개념으로 본다.

학교준비도는 읽기, 쓰기, 셈하기 등 학습과제수행과 관련 된 기초학습능력인 학습준비도(learning readiness)와는 구별된 다(Bang \& Hwang, 2013). 학교준비도의 구성영역은 사회정서 행동, 의사소통, 학업에 대한 태도, 인지발달 및 일반적 지식 등 학교환경 적응 및 그에 따른 발달적 준비에 필요한 총체적 개념이다. 즉, 아동의 발달과 학습, 이전보다 정형화되고 확장 된 학교라는 사회적 체계로의 이행 및 상호작용에 필요한 발 달적 영역이며(Y. Cho, 2018), 사회적 적응 및 수행과 추후 아 동의 문제행동을 예측하는 중요한 요인으로 강조된다(Pears, Carpenter, Kim, Peterson, \& Fisher, 2018). 학령초기의 학교적응 은 학업적 측면과 학교생활 측면으로 구분하는데, 우리나라의 경우에는 학업적 측면에서 성공적인 수행을 하지 못할 경우 학교적응 전반에 어려움을 겪을 가능성이 높다고 본다. 실제 로 우리나라 초등학생들은 학업수행에 대한 부담감 및 스트레 스를 많이 겪고 있는 것으로 보고되었다(Y. Kim, Kim, Choi, \& Yoo, 2013). 초기 학교적응의 어려움은 정서적 위축이나 우울 등 내재화된 문제행동이나 비행이나 학업 중단 등 외현화된 문제행동으로 이어질 가능성이 높으며(Y. S. Cho \& Lee, 2010), 아동기 이후의 사회정서 및 인지발달, 사회적 성공에도 영향 을 미친다는 연구결과(Hughes, 2011; Jung \& Chi, 2006) 등을 고려할 때 취학전 아동의 학교준비도에 영향을 주는 요인 및 그 발달경로를 이해하는 것은 예방적 차원에서의 지원방안을 모색하는 데 매우 중요한 기초자료가 될 것으로 본다.

학습태도 및 수행, 학교생활 적응 등 학교적응 전반을 예측 하는 요인으로 스스로를 규제하고 조절하는 능력을 강조한 다(Murphey \& Burns, 2002). 조절능력이 높을 경우 학습태도 가 긍정적이며 문해 및 수학과제 수행 결과가 긍정적(Blair \& Razza, 2007)인 반면, 조절능력이 낮으면 학습태도나 이해력, 그리고 인지적 추리 및 수리적 과제의 수행점수가 낮고(Spira
\& Fischel, 2005), 또래 및 사회적 관계에서 친사회적 성향이 적 으며 공격적이고 지시를 잘 따르지 않으며(Guralnick, 1992), 적절한 의사소통을 통해 감정이나 생각을 표현하기 어려워하 였다(K.-P. Hong \& Jo, 2015). 이는 아동의 조절능력이 이전보 다 정형화되고 확장된 학교환경에 적응하여 바람직한 학습태 도와 성공적인 학업수행, 사회적 관계에서의 긍정적인 상호작 용에 핵심 변인임을 뒷받침한다.

최근 뇌신경발달 연구의 발전으로 인간의 행동과 두뇌 영 역간의 관계에 대한 과학적 증거들이 제시되면서 조절능력 또한 이를 관장하는 두뇌 영역 간의 활발한 교류를 통해 발달 한다는 견해가 우세해졌다. 즉, 다양하고 풍부한 경험과 활동 을 통해서 뇌의 영역 간 연결망이 구축되고 활성화되며, 조 절능력 역시 그러한 과정을 거쳐 발달한다는 것이다(Tarullo, Obradović, \& Gunnar, 2009). 이러한 연구는 애착이론에서 강 조하는 민감한 양육, 따뜻하고 지지적인 상호작용이 발달 전 반에 가장 기본적이고 필수적인 경험임을 뒷받침한다. Bowlby (1969)는 내적작동모델(internal working model)을 설명하면서 유기체가 자신이 처한 환경에 효과적으로 적응하기 위해서 환 경 및 자신을 통제하려는 과정을 강조하였다. 이는 스스로 상 황을 미리 시뮬레이션 해 보는 정신 구조의 역동적 측면을 의 미한다. Lopez와 Brennan (2000)은 Bowlby의 이러한 견해를 확 장시켰다. 즉, 영아는 양육경험을 내적작동모델에 자신이나 타인에 대한 표상을 저장할 뿐만 아니라 애착욕구나 양육자의 반응패턴으로 발생한 정서에 자신이 반응하는 암묵적인 행동 전략을 규칙으로 부호화하여 저장한다는 것이다. 이러한 암묵 적 규칙을 Wallin (2007)은 영아가 초기 양육자와의 관계에 적 응하는 애착전략으로 보았으며, Fonagy와 Target (1997)은 암 묵적(implicit) 기억에 의해 애착전략이 내적작동모델에 규칙 으로 부호화되어 저장된다고 설명하였다. 정보처리가 암묵적 기억으로 진행될 때 정서와 행동 조절은 자동적으로 익숙해진 패턴으로 작동하며, 감각적이고 절차적 과정에서 작동하는 자 동적 표상은 스스로 의식하거나 언어로 표현하기 힘들기 때문 에 행동이나 동작 등 비언어적인 패턴으로 표출되는 경향이 있다(J. Kim, 2013).

애착관련 연구들은 자녀의 욕구를 민감하게 알아채고 일관 적으로 따뜻하게 수용하는 민감한 양육이 생애 전반에 걸쳐 자신 및 타인에 대한 평가, 환경 및 대인관계에 대한 기대 및 해석 등 발달 및 적응 전반에 영향을 미치는 일차적인 핵심 요 인임을 뒷받침한다. 양육 민감성이 높은 어머니의 영아는 애 착욕구가 충족되고 정서가 안정되어 탐색행동이 촉진되며 $(\mathrm{H}$. M. Lee, Park, \& Seo, 2008), 자신과 환경에 대한 조절감을 느끼 
고(Bowlby, 2005), 자신의 부정적 정서를 다 잘 다룰 수 있었다 (Field, Diego, \& Hernandez-Reif, 2006). 반면, 양육민감성이 낮 은 어머니의 영아들은 공동주의(joint attention) 수준이 낮으며 (Gaffan, Martins, Healy, \& Murray, 2010), 운동 및 정서 발달의 지연(Murray \& Cooper, 1997), 유아기 분리불안 및 학령기 또 래관계 어려움, 내재화 또는 외현화 문제행동으로 이어질 가 능성이 높았다(Kam et al., 2011).

애착관련 연구들은 또한 민감한 양육을 통해 긍정적인 내 적작동모델이 발달하는 과정에서 조절능력도 발달한다는 Bowlby (1969)의 견해를 뒷받침한다. 이는 학교준비도의 중요 변인인 조절능력 발달의 전제 조건이 어머니의 민감한 양육임 을 의미한다(H. J. Park, Lee, Choi, \& Bang, 2005). 조절능력 중 특히 자신의 정서를 조절하는 능력은 문제행동과 가장 관련성 이 높다(Seo \& Shim, 2016)는 점에서 본 연구에서는 학교준비 도와 관련된 조절능력으로 정서조절능력에 초점을 두었다. 정 서조절능력이 미숙할 경우 주변으로부터 부정적인 피드백을 야기하여 위축 또는 공격성을 유발시켜 문제행동으로 이어지 기 때문이다.

애착점수가 높을수록 아동의 정서조절능력이 높음을 보고 한 연구들(Hwang \& Bang, 2012; S. A. Kim \& Park, 2009; Seo \& Shim, 2016)은 어머니의 민감한 양육태도가 정서조절능력 발 달의 전제조건임을 뒷받침한다. 양육 민감성의 중요한 측면 인 온정적 양육행동을 통해 자녀와 긍정적인 감정을 교류하는 것은 자녀가 내적인 기쁨을 경험하는 데 중요한 역할을 하며 (MacDonald, 1992), 그 과정에서 부모가 정서조절 방법을 직 접 가르치거나 모델을 제공하여 자녀의 정서조절을 돕게 된 다(Isley, O’Neil, Clatfelter, \& Parke, 1999). 더 나아가 온정적 양 육행동은 자녀로 하여금 긍정 정서를 경험하게 하여 양육자에 게 관심을 기울이게 하고 순응하면서 자신의 행동을 조절할 수 있게 하며(Yoo \& Kim, 2017), 어머니의 온정적 양육 수준이 낮을수록 아동의 내재화 또는 외현화 문제행동 수준이 높다 는 연구결과(Choi, Yoon, \& Yeon, 2016; W. K. Lee, Kim, \& Yun, 2018)는 민감한 양육이 자녀의 정서조절능력에 영향을 미친 다는 입장과 그 맥을 같이 한다.

부모가 자녀를 따뜻하게 대하고 합리적으로 반응하면 부 모자녀관계가 긍정적으로 형성되고, 자녀의 사회적 상호작용 에 필요한 능력 및 학업수행을 위한 기초학습능력 등 인지적 기술 발달로 이어져 학교준비도를 높인다는 점에서(J. A. Lee, Park, Chung, \& Yi, 2017), 민감한 양육과 학교준비도 간의 관 련성을 학습준비도와 정서조절능력 간의 관련성과 함께 고려 하면 민감한 양육이 학교준비도에 영향을 주는 경로에 정서조
절능력의 매개효과가 있을 것으로 본다. 어머니의 민감한 양 육은 또한 기질적으로 부정적 정서성이 높은 영아에게 보호요 인으로 작용할 것으로 본다. 예민하고 잘 우는 등 부정적 정서 성이 높은 영아가 강압적이고 거부적인 양육을 경험하면 그렇 지 않은 영아에 비해 이후 정서 및 행동문제를 더 많이 보였으 며(Belsky, Hsieh, \& Crnic, 1998; Morrell \& Murray, 2003), 기질 적으로 부정적 정서성이 높은 유아에게 지지적이고 민감한 양 육 경험을 제공하는 중재프로그램을 실시했을 때 그 효과가 가장 높았음이 보고되었다(Pluess \& Belsky, 2010).

앞에서 살펴본 연구결과들은 자녀의 건강한 발달을 촉진시 키는 일차적인 환경은 가정이며, 특히 주 양육자인 어머니의 영향력을 강조한다. 애착이론에서 강조하는 중요한 영향 요인 인 어머니의 민감하고 반응적인 양육행동은 어머니의 정서적 건강과 밀접하게 연관된다. 어린 자녀를 돌보는 어머니에게 서 나타날 수 있는 대표적인 정서적 위험 요인 중 하나로 양육 스트레스를 들 수 있다. 양육스트레스가 높아지면 자녀에 대 해 부정적인 감정이 높아지고(Suchman \& Luthar, 2001), 중추 신경계 및 호르몬 분비변화로 인해 정서조절이 어려워져 온 정적이고 수용적인 태도가 줄고 강압적인 태도를 취하게 된다 (Bugental, Olster, \& Martorell, 2003).

어머니의 양육스트레스는 자녀의 정서관련 문제 및 또래관 계에 직접적으로 영향을 미치며(J. Yoon, 2017), 일상적인 양육 행동에도 반영되어 부적절한 상호작용을 매개로 자녀의 적응 및 발달에 간접적으로 영향을 미친다(Deater-Deckard, 1998). 출산 후 4 년간 어머니의 양육스트레스 변화궤적에 대한 연구 (S. Park \& Park, 2016)를 통해서 어머니의 양육스트레스는 자 녀가 만 3세가 되었을 때 부정적 정서표현 증가 및 또래와의 긍정적 상호작용 감소에 직접 영향을 미치며, 어머니의 온정 적 양육행동 감소에도 영향을 미쳐 긍정적 또래 상호작용 감 소에 간접 영향이 있음이 보고되었다. 이러한 결과는 양육스 트레스가 높을 경우 자녀의 신체적, 정서적 요구에 민감하게 반응하지 못하고, 이로 인해 자녀의 요구가 더 많아지게 되고 예민해지며 부정적 정서성이 더 높아지는 결과로 이어져, 결 과적으로 또래와의 부정적 상호작용이 증가한 것으로 해석될 수 있다. 양육스트레스는 또한 자녀와의 상호작용에 부정적인 영향을 미쳐 학업수행 및 학교생활 적응의 어려움으로 이어지 는 것으로 보고되었다(Y. Kim, Koo, \& Kim, 2019; J. Yoon, Lee, \& Lee, 2017).

양육스트레스는 선행연구에서 주로 양육행동 및 자녀의 사 회정서발달에 영향을 미치는 설명변인으로 다루어져 왔다. 그 러나 그 경로의 역방향, 즉 양육스트레스를 자녀의 부정적 정 
서표현 증가로 인한 반응변인으로 설명한 연구(Kwon, 2011) 도 있다. 반응변인으로서 양육스트레스를 다루는 경우, 양육 스트레스가 높을수록 자녀의 정서성, 즉 자녀의 정서표현을 어머니가 더 부정적으로 지각했을 가능성도 있으나(S. Park \& Park, 2016), 다른 한편으로는 자녀의 부정적 정서표현 증가로 인해 어머니의 양육스트레스 증가되었을 수도 있다. 민감하고 반응적인 양육행동은 기질적으로 예민하고 부정적 정서성이 높은 자녀의 보호요인으로 작용한다는 선행연구결과(Belsky et al., 1998; Morrell \& Murray, 2003; Pluess \& Belsky, 2010)는 양 육민감성이 양육스트레스를 낮춰주는 보호요인이 될 수 있음 을 뒷받침한다. 즉, 민감한 양육이 자녀의 건강한 발달을 촉진 시킴으로써 양육의 어려움이 줄어들고 부모역할을 적절하게 하고 있다는 양육효능감이 높아져서 양육에 대한 스트레스가 줄어들 수 있다. 이러한 견해는 양육의 민감성을 높이는 부모 교육 프로그램을 통해 자녀의 부정적 정서성을 낮춘다면 양육 스트레스 또한 감소시키는 효과가 있음을 시사한다.

이상을 종합해볼 때 학령기 전이시기의 학교적응과 이후의 사회적 적응 및 성취수준에 중요한 발달지표인 학교준비도에 영향을 미치는 아동의 정서조절능력은 어머니의 양육행동과 밀접하게 관련됨을 알 수 있다. 또한 민감한 양육은 양육스트 레스를 감소시킬 수 있으며, 부정적 정서성 등 유아의 기질적 태도에도 긍정적인 영향을 미쳐서, 이를 매개로 하여 유아의 정서조절능력을 높이는 효과가 있을 것으로 본다.

선행연구를 통해 학교준비도와 관련된 요인으로 양육행동, 양육스트레스 등을 포함한 가정양육환경 변인, 그리고 유아의 기질, 정서조절능력 등을 포함한 개인적 변인들의 개별적 또 는 상대적 영향력을 확인한 연구는 많으나, 학교준비도에 영 향을 미치는 주요 변인으로 양육민감성에 초점을 두고, 양육 스트레스 및 유아 기질의 매개 효과 및 정서조절능력의 매개 효과를 연계하여 순차적으로 살펴본 연구는 찾아보기 매우 힘 들다. 따라서 본 연구에서는 학교준비도에 영향을 미치는 일 차적인 요인을 어머니의 양육민감성으로 가정하고, 그 경로 에서 어머니의 양육스트레스 및 유아 기질의 매개 효과와 유 아 정서조절능력의 연속다중매개효과(serial multiple mediation effect)를 검증하고자 하였다. 이를 통해 본 연구는 학령기로의 전이시기에 학교적응에 중요한 학교준비도를 높이기 위해서 는 부모교육이 중요함을 강조하고, 그 초점을 양육민감성에 둔 프로그램을 적극적으로 개발할 수 있도록 그 기초자료를 제공하고자 하였다.

본 연구의 가설모델(Figure 1)에 따른 구체적인 연구문제는 다음과 같다.

\section{연구문제 1}

양육만감성과 양육스트레스, 유아의 기질, 정서조절능력, 학 교준비도 간에 영향관계는 어떠한가?

\section{연구문제 2}

양육스트레스와 기질이 양육민감성과 정서조절능력을 매개 하는가?

\section{연구문제 3}

정서조절능력이 양육스트레스 및 기질과 학교준비도를 매개 하는가?

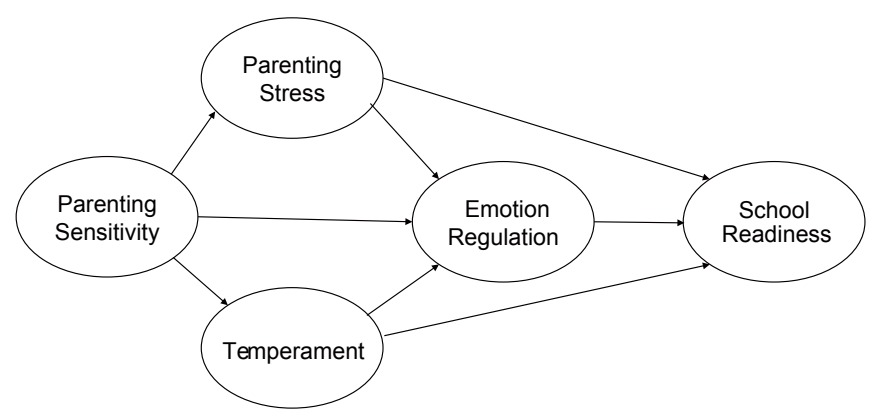

Figure 1. The model for the hypothesis.

\section{Methods}

\section{연구대상}

본 연구는 K도에 소재한 유치원 및 어린이집 12 개 기관의 만 5 세반 20학급의 어머니 및 담임교사를 대상으로 하였다. 각 학 급 전체 아동의 가정으로 어머니용 질문지 총 400 부를 배부하 였고, 그 중 회수된 286명의 아동에 대해 각 아동의 담임교사 가 교사용 질문지를 작성하였다. 어머니용 질문지와 교사용 질문지가 모두 회수된 286명 중 자료 분석 대상은 총 271명이 었다. 남자아동 150 명(55.4\%), 여자아동 121 명(44.6\%)이었으 며, 모의 연령은 27-35세 73명(27\%), 36-43세 178명(65.8\%), 44-52세 19명(7\%), 53세 이상 1 명(0.4\%)이었고, 교사의 연령 은 23-30세 146명(53.9\%), 31-40세 37명(13.7\%), 50세 이상 16 명(6\%)이었다(Table 1). 
Table 1

Participants Socio-Demographic Characteristics

\begin{tabular}{llr}
\hline \multicolumn{1}{c}{ Characteristics } & \multicolumn{1}{c}{ Subcategories } & $n(\%)$ \\
\hline Child's gender & Male & $150(55.4 \%)$ \\
& Female & $121(44.6 \%)$ \\
Mother's age & $27-35$ & $73(27.0 \%)$ \\
& $36-43$ & $178(65.8 \%)$ \\
& $44-52$ & $19(7.0 \%)$ \\
Teacher's age & $53+$ & $1(0.4 \%)$ \\
& $23-30$ & $146(53.9 \%)$ \\
& $31-40$ & $37(13.7 \%)$ \\
& $41-50$ & $72(26.6 \%)$ \\
& $50+$ & $16(6.0 \%)$ \\
\hline Total & & $271(100.0 \%)$ \\
\hline
\end{tabular}

Note. $N=271$.

\section{연구도구}

\section{양육민감성 측정도구}

어머니의 양육민감성은 한국아동패널연구 1 차년도 조사부 터 사용된 양육행동척도(the Parental Style Questionnaire [PSQ]; Bornstein et al., 1996) 중 사회적 양육유형 하위척도로 측정하 였다. PSQ는 총 17 문항으로, 사회적 양육유형 (social interation) 9문항, 가르치는 양육유형(didactic/material stimulation) 5문항, 한계설정 양육유형(limit setting) 3문항으로 구성되어 있다. 사 회적 양육유형은 어머니가 실제로 자녀와 주고받는 관계적 상 황에서의 양육행동을 의미하는 것으로 어머니의 온정성 및 반 응성을 포함하는 개념이다. Bowlby (1969)는 안정애착 형성 을 위한 어머니의 민감한 양육태도를 따뜻함, 수용적이고 지 지적임, 조율적인 반응으로 개념화하므로, 본 연구에서는 이 러한 온정성 및 반응성을 양육의 민감성으로 개념화하였다. Likert식 5점 척도이며, 점수가 높을수록 어머니의 양육민감성 이 높음을 의미한다. 본 연구에서 나타난 척도의 내적 합치도 Cronbach's $\alpha$ 는 .86이었다.

$$
\text { 양육스트레스 측정도구 }
$$

어머니의 양육스트레스는 K. H. Kim과 Kang (1997)이 개발한 양육스트레스 척도(Parenting Stress Scale [PSS]) 중 '부모역할 수행의 부담감 및 디스트레스' 요인에 해당하는 문항으로 측 정하였다. 원 도구는 이 요인 외에 '자녀양육으로 인한 일상적
스트레스' 및 '타인양육에 대한 죄책감' 요인을 포함하여 구성 되어 있으나, 한국아동패널연구 3 차년도부터 포함된 양육스 트레스 조사 시 PSS 중 부모역할 수행의 부담감 및 디스트레 스 요인만 측정하였고, 본 연구에서도 이 요인을 양육스트레 스의 대표적 요인으로 간주하였다.

원 도구에서는 부모역할 수행의 부담감 및 디스트레스 요 인이 12 문항으로 구성되어 있으나 한국아동패널연구에서는 2007년도의 예비조사 결과를 토대로 문항진술이 명확하지 않 은 1 문항을 제외한 11 문항을 사용하였고, 본 연구에서도 그 11 문항을 사용하였다. Likert식 5점 척도이며, 점수가 높을수 록 부모역할 수행에 대한 부담감 및 디스트레스가 높음을 의 미한다. 본 연구에서 나타난 척도의 내적 합치도 Cronbach's $\alpha$ 는 .91 이었다.

$$
\text { 유아기질 측정도구 }
$$

유아의 기질은 한국아동패널연구 3 차년도 이후 조사부터 사용된 the Emotionality, Activity and Sociability-temperament survey for children-parental ratings (EAS; Mathiesen \& Tambs, 1999 )로 측정하였다. 총 20 문항으로, 정서성(emotionality) 5 문 항, 활동성(activity) 5문항, 사회성(shyness/sociability) 10 문항으 로 구성되어 있다. Likert식 5점 척도이며, 정서성 점수가 높을 수록 부정적 정서를 많이 나타내며, 활동성 점수는 높을수록 움직이길 좋아하고 활동적인 특성이, 사회성 점수는 타인과 잘 어울리며 덜 수줍어하는 특성이 높음을 의미한다. 본 연구 에서는 정서성 5문항에 대한 원도구의 채점방식을 역으로 산 출하여 점수가 높을수록 부정적 정서 표현이 적음을 의미하는 것으로 변환하여 분석하였다. 본 연구에서 나타난 척도의 내 적 합치도 Cronbach's $\alpha$ 는 .77였으며, 하위영역별로는 정서성 .77 , 활동성 .76 , 사회성 .82 이었다.

$$
\text { 유아 정서조절 측정도구 }
$$

유아의 정서조절은 Rothbart, Ahadi와 Hershey (1994)가 3-7 세 유아를 대상으로 개발한 아동행동질문지(Chid Behavior Questionnaire [CBQ]) 중 의도적 통제에 해당하는 문항을 선별 하여 사용하였다. 부모용 관찰척도로서 총 27 문항이며, 하위 척도는 ‘주의집중하기' 9문항, ‘통제하기' 13 문항, ‘주의전환하 기' 5문항으로 구성되어 있다. $\mathrm{CBQ}$ 는 관찰을 통해 부모가 유 아의 의도적 통제능력을 측정하기에 용이한 도구로 평가되고 있다(Moon, 2010). Likert식 5점 척도이며, 점수가 높을수록 정 
서조절능력이 높음을 의미한다. 본 연구에서 나타난 척도의 내적 합치도 Cronbach's $\alpha$ 는 .84였으며, 하위영역별로는 주의 집중하기 .66, 통제하기 .79, 주의전환하기 .70이었다.

\section{학교준비도 측정도구}

학령 전 유아의 학교준비도는 한국아동패널연구 7차년 조사 에서 사용된 학교준비도(school readiness)의 일부를 사용하여 측정하였다. 원 척도는 Murphey와 Burns (2002)가 개발한 척 도로서 사회정서발달 6 문항, 학습에 대한 태도 8 문항, 의사소 통 3 문항, 인지발달 및 일반적 지식 5 문항 총 22 문항이다. 본 연구에서는 기질척도의 사회성 문항들과 유사한 사회정서발 달 영역 6 문항을 제외하고 3 개 하위영역 16 문항만 사용하여 담임교사가 평가하도록 하였다. Likert식 4점 척도이며, 점수 가 높을수록 학교준비도가 높음을 의미한다. 본 연구에서 나 타난 척도의 내적 합치도 Cronbach's $\alpha$ 는 .93이었고 하위영역 별로는 학습에 대한 태도 .90 , 의사소통 .86 , 인지 및 일반적 지 식 .79이었다.

\section{연구절차}

본 연구는 2019년 6월 12일부터 7월 15일까지 K도 소재 유치 원과 어린이집 어머니 및 담임교사를 대상으로 자료를 수집하 였다. 1 차적으로 각 학급의 전체 유아 가정으로 양육민감성, 양육스트레스, 유아의 기질 및 정서조절을 평가하는 어머니 용 질문지를 배부하였다. 그 중 질문지가 회수된 유아를 대상 으로 학교준비도를 평가하는 교사용 질문지를 배부하였다. 두 질문지가 모두 회수된 대상은 총 286명이었으나 그 중에서 일 관응답 또는 무선응답을 한 대상을 제외시킨 271 명의 자료를 최종 분석 대상으로 하였다.

구조방정식모델 추정법 중의 하나인 최대우도법(maximum likelihood)을 사용하기에 표본의 크기가 150-400정도가 적당 하기 때문에(Hair, Black, Babin, \& Anderson, 2009), 본 연구에 서는 1 차적으로 20 학급 총 400 명을 대상으로 어머니용 질문 지를 배부하였다. 질문지를 배부하기 전에 기관장 및 담임교 사에게 연구의 목적을 설명한 뒤 어머니용 질문지를 배부하였 고, 질문지 배부와 함께 연구의 목적 및 동의서도 함께 배부하 였다. 어머니 동의서에는 자녀에 대한 담임교사의 평가를 연 구에 사용하는 것에 대한 동의도 포함되었다. 교사의 동의서 도 교사용 질문지를 배부할 때 포함되었다.

\section{자료분석}

본 연구에서는 첫째, 수집된 데이터를 바탕으로 변인들의 평 균 및 표준편차 그리고 왜도와 첨도를 산출하였고 주요 변인 들 간의 상관을 알기 위해 PASW 18.0 (SPSS Inc., Chicago, IL) 를 사용하여 기술통계, 상관분석을 실시하였다. 둘째, 측정할 변인 간의 구조관계를 검정하기 위해 AMOS 18.0 (IBM Co., Armonk, NY)를 사용하여 가설의 검증은 양측검정(two-tailed) 을 선택했고 유의수준이 .05일 때, 경로계수들의 유의성은 C.R.(검정통계량) 값이 1.96 이상이면 통계적 유의확률이 높 게 된다. 모델 적합도 검정은 모형의 전반적인 적합/부합도를 평가하는 절대적합지수(absolute fit index)인 카이제곱 $\left(\chi^{2}\right)$ 검 정, GFI, AGFI, RMSEA 지수로 보고하였다. 그리고 연구모델 이 영모델(null model)에 비해 얼마나 측정되었는지는 증분적 합지수(incremental model)인 CFI, NFI의 값(Browne \& Cudeck, 1992; Byrne, 2009; S. Hong, 2000)을 통해 평가하였다. 각 지 수는 $\chi^{2}$ 의 $p$-value < .05, $0.5<$ RMSEA < 0.8, AGFI, GFI > 0.9, $\mathrm{NFI}, \mathrm{CFI}>0.9$ 의 기준으로 평가하였다. 변인들 간의 직접효과 와 간접 효과의 유의수준은 $p<.05$ 에서 검증하였다. 본 연구 의 다중매개효과 검정은 Sobel (1982) 검정방법을 선택하였고 $Z$ 값 통해 각각의 간접경로의 유의성을 보고하였다.

\section{Results}

\section{측정변인간의 상호상관행렬 및 기술 통계치}

구조방정식의 정규성 분포를 가정하기 위해 Table 2에서 보는 바와 같이 다변인정규분포성을 검증한 결과 왜도와 첨도 절대 값이 3-10을 넘지 않아 정규성을 위배하지 않는 것으로 판단 된다(Kline, 2015). Table 3에 제시된 것과 같이 연구모델의 측 정변인과 잠재변인들 간의 표준화된 회귀계수는 $p<.001$ 수 준에서 통계적으로 유의미한 것으로 드러났다. 마지막으로 측 정변인 간의 관계를 분석하기 위하여 피어슨의 상관분석을 실 시하였으며 이는 Table 4 에 제시하였고 결과는 다음과 같다. 먼저, 양육민감성은 양육스트레스와 유의미한 부적상관을 보 였으며 $(r=-.465, p<.01)$, 기질과 유의미한 정적상관을 보였다 $(r=.145, p<.05)$. 또한 양육민감성은 정서조절과 유의미한 정 적상관을 보였다 $(r=.424, p<.01)$. 양육스트레스는 정서조절 과 유의미한 부적상관을 보였다 $(r=-.390, p<.01)$. 정서조절은 학교준비도와 유의미한 정적상관을 보였다 $(r=.222, p<.01)$. 
Table 2

The Mean, Standard Deviation, Skewness, and Kurtosis of the Measured

\begin{tabular}{|c|c|c|c|c|c|}
\hline Variables & Parenting sensitivity & Parenting stress & Temperament & Emotion regulation & School readiness \\
\hline$S D$ & .43 & .63 & .40 & .40 & .42 \\
\hline Skewness & -.143 & .427 & -.106 & .109 & -.935 \\
\hline Kurtosis & .074 & .203 & .160 & -.052 & .696 \\
\hline
\end{tabular}

Note. $N=271$.

Table 3

Estimation and Statistical Significance of the Final Model

\begin{tabular}{|c|c|c|c|c|}
\hline Path & $B$ & $S E$ & C.R. & $\beta$ \\
\hline Parenting sensitivity $\rightarrow$ Sen 2 & .762 & .077 & 9.92 & $.68^{* * *}$ \\
\hline Parenting sensitivity $\rightarrow$ Sen 3 & .840 & .082 & 10.26 & $.71^{* * *}$ \\
\hline Parenting stress $\rightarrow \mathrm{S} 1$ & 1 & & & $.80^{* * *}$ \\
\hline Parenting stress $\rightarrow$ S3 & .966 & .076 & 12.73 & $.80^{* * *}$ \\
\hline Temperament $\rightarrow \mathrm{T} 1$ & 1 & & & $.90^{* * *}$ \\
\hline Temperament $\rightarrow \mathrm{T} 2$ & 1.46 & .143 & 10.19 & $.75^{* * *}$ \\
\hline Temperament $\rightarrow$ T3 & 1.42 & .143 & 9.93 & $.90^{* * *}$ \\
\hline Emotion regulation $\rightarrow$ Em3 & .76 & .108 & 7.082 & $.53^{* * *}$ \\
\hline School readiness $\rightarrow$ Sc1 & 1 & & & $.89^{* * *}$ \\
\hline School readiness $\rightarrow$ Sc2 & .466 & .054 & 8.632 & $.58^{* * *}$ \\
\hline School readiness $\rightarrow$ Sc3 & .612 & .060 & 7.066 & $.77^{* * *}$ \\
\hline
\end{tabular}

Note. $N=271$.

*** $p<.001$.

Table 4

The Correlation Matrix for the Measured Variables

\begin{tabular}{|c|c|c|c|c|c|}
\hline Variables & 1 & 2 & 3 & 4 & 5 \\
\hline 2. Parenting stress & $-.465^{* *}$ & - & & & \\
\hline 3. Temperament & $.145^{*}$ & -.011 & - & & \\
\hline 4. Emotion regulation & $.424^{* *}$ & $-.390^{* *}$ & .035 & - & \\
\hline
\end{tabular}

Note. $N=271$.

${ }^{*} p<.05 .{ }^{* *} p<.01$. 
Table 5

The Goodness of Fit Index and Parsimony Index of the Model

\begin{tabular}{cccccccc}
\hline$\chi^{2}$ & $d f$ & $\chi^{2} / d f$ & GFI & AGFI & NFI & CFI & RMSEA [CI] \\
\hline $140.812^{* * *}$ & 82 & 1.717 & .939 & .910 & .909 & .959 & $.052[.037 \sim .066]$ \\
\hline
\end{tabular}

${ }^{* * *} p<.001$.

Table 6

Estimation of the Model Parameters and Statistical Significance of the Model

\begin{tabular}{lcccc}
\hline \multicolumn{1}{c}{ Path } & $B$ & $S E$ & C.R. & \multicolumn{1}{c}{$\beta$} \\
\hline Parenting sensitivity $\rightarrow$ Parenting stress & -.76 & .11 & -7.18 & $-.56^{* * *}$ \\
Parenting sensitivity $\rightarrow$ Temperament & .11 & .05 & 2.31 & $.17^{*}$ \\
Parenting sensitivity $\rightarrow$ Emotion regulation & .30 & .08 & 4.01 & $.39^{* * *}$ \\
Parenting stress $\rightarrow$ Emotion regulation & -.16 & .05 & -3.22 & $-.29^{* *}$ \\
Parenting stress $\rightarrow$ School readiness & .10 & .08 & 1.22 & .11 \\
Temperament $\rightarrow$ Emotion regulation & -.06 & .08 & -1.06 & -.07 \\
Temperament $\rightarrow$ School readiness & .21 & .14 & 1.56 & .11 \\
Emotion regulation $\rightarrow$ School readiness & .48 & .15 & 3.24 & $.30^{* *}$ \\
\hline Note
\end{tabular}

Note. $N=271$.

${ }^{*} p<.05 .{ }^{* *} p<.01 .{ }^{* * *} p<.001$.

Table 7

The Standardized Total Effect, Direct Effect, and Indirect Effect of Each Path of the Model

\begin{tabular}{|c|c|c|c|c|}
\hline Path & Total effect & Direct effect & \multicolumn{2}{|c|}{ Indirect effect } \\
\hline Parenting sensitivity $\rightarrow$ Parenting stress & $-.561^{* *}$ & $-.561^{* * *}$ & \multicolumn{2}{|c|}{-} \\
\hline Parenting sensitivity $\rightarrow$ Temperament & $.172^{*}$ & $.172^{*}$ & \multicolumn{2}{|c|}{ - } \\
\hline \multirow[t]{2}{*}{ Parenting sensitivity $\rightarrow$ Emotion regulation } & $.545^{* *}$ & $.404^{* * *}$ & $.152^{*}$ & $.141^{*}$ \\
\hline & & & -.011 & \\
\hline Parenting sensitivity $\rightarrow$ School readiness & $.116^{*}$ & - & \multicolumn{2}{|c|}{$.116^{*}$} \\
\hline Parenting stress $\rightarrow$ Emotion regulation & $-.272^{* *}$ & $-.272^{* *}$ & \multicolumn{2}{|c|}{ - } \\
\hline Parenting stress $\rightarrow$ School readiness & .010 & .081 & \multicolumn{2}{|c|}{$-.071^{*}$} \\
\hline Temperament $\rightarrow$ Emotion regulation & -.067 & -.067 & \multicolumn{2}{|c|}{ - } \\
\hline Temperament $\rightarrow$ School readiness & .090 & 107 & \multicolumn{2}{|c|}{-.018} \\
\hline Emotion regulation $\rightarrow$ School readiness & $.262^{* *}$ & $.262^{* *}$ & \multicolumn{2}{|c|}{ - } \\
\hline
\end{tabular}

Note. $N=271$.

${ }^{*} p<.05 .{ }^{* *} p<.01 .{ }^{* * *} p<.001$.

\section{연구 모델 적합도 평가 결과}

연구모델의 지수판단기준은 적합도와 간명도라고 할 수 있 는데, 상대적 부합도 평가지표 TLI, CFI, RMSEA를 사용하여 연구모델의 적합도를 평가하였다. 적합도 지수 기준은 TLI와 $\mathrm{CFI}$ 는 .90 이상이면 모델의 적합도가 좋은 것으로 간주된다(S. Hong, 2000). 연구모델의 RMSEA의 적당한 모형 지수는 .05 .08 이하이면 가능하고 간주된다. Table 5 에서 제시된 것처 럼 연구모델의 적합도를 추정한 결과, $\chi^{2}=140.812(d f=82, p$
$<.001), \chi^{2} / d f=1.717\left(\chi^{2} / d f<2\right)$, AGFI $=.910$, GFI $=.939$, NF I $=.909, \mathrm{CFI}=.959, \mathrm{RMSEA}=.052$ 로 모든 적합도 기준에 양호 하게 부합되는 것으로 나타났다.

\section{모델검정 결과}

본 연구 모델의 모수치 추정결과는 Table 6, 모델의 표준화된 각 경로의 직접효과, 간접효과, 총효과는 Table 7에 제시하였 다. 본 연구의 결과는 Table 6에서 제시된 것처럼 첫째, 양육민 


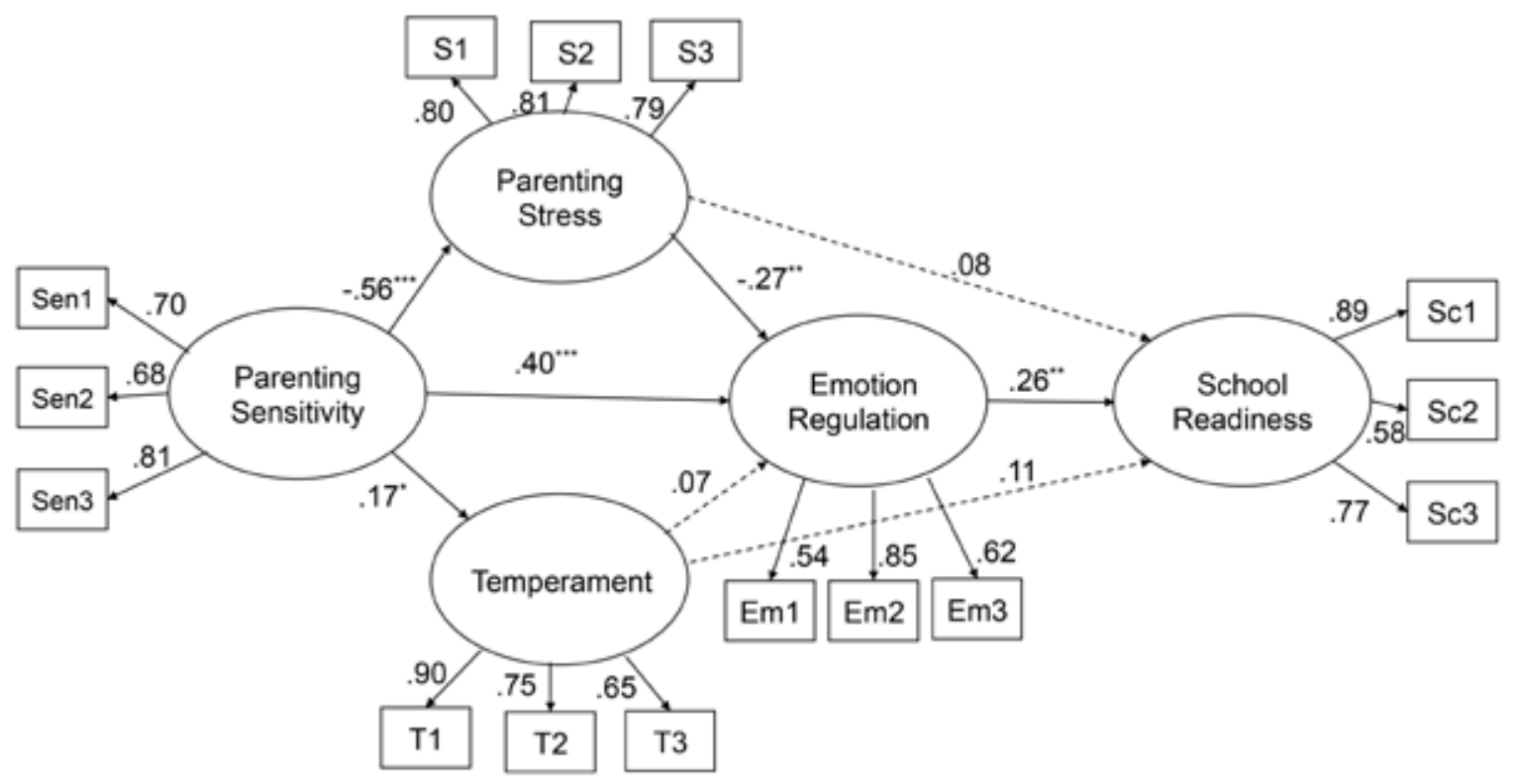

Figure 2. Standardized factor estimation of the research model.

${ }^{*} p<.05 .{ }^{* *} p<.01 .{ }^{* * *} p<.001$.

감성은 양육스트레스 $(\beta=-.56, p<.001)$, 기질 $(\beta=.17, p<.05)$, 정서조절 $(\beta=.26, p<.001)$ 모두에 유의미한 직접적 영향을 주었다. 둘째, 양육민감성은 양육스트레스를 부분매개(partial mediation)하여 정서조절에 영향을 주었다 $(\beta=.15, Z=3.72, p$ <.001). 그러나 양육민감성은 기질을 매개하지 않았고 정서 조절에도 영향을 주지 않았다 $(\beta=-.01, Z=-0.80, p>.05)$. 또 한 양육민감성은 정서조절을 매개하여 학교준비도에 영향을 미치는 것 $(\beta=.12, Z=1.68, p<.05)$ 으로 나타났다. 셋째, 양육 스트레스는 정서조절을 완전매개(full mediation)하여 학교준 비도에 영향을 미치는 것으로 나타났다 $(\beta=-.07, Z=-1.68, p<$ $.05)$. 그러나 기질은 정서조절을 매개하지 않았고 학교준비도 에도 영향을 주지 않았다 $(\beta=-.02, Z=-0.75, p>.05)$. 본 연구 모델의 모수치 추정결과와 유의성 검증결과를 Figure 2에서 그 림으로 제시하였다.

\section{Discussion}

본 연구는 어머니의 양육민감성이 유아의 학교준비도에 미치 는 영향을 알아보고, 그 관계에서 어머니의 양육스트레스, 유 아의 기질 및 정서조절능력의 매개효과를 검증하고자 하였다. 이를 통해 유아의 학교준비도에 미치는 주요 변인을 밝히고, 유아의 학교준비도를 향상시키기 위한 기초자료를 제공하고
자 하였다. 본 연구에서 나타난 주요 결과와 그에 따른 논의는 다음과 같다.

첫째, 어머니의 양육민감성은 어머니의 양육스트레스, 유 아의 기질 및 정서조절능력에 직접적인 영향을 미쳤다. 즉, 어 머니가 온정적이고 반응적으로 양육할 때 양육스트레스가 낮 았으며, 낮아진 양육스트레스는 정서조절능력에 영향을 미치 는 양육의 민감성을 부분매개하는 효과가 있었다. 또한 어머 니의 양육민감성은 유아의 부정적 정서성을 낮추고 활동성 및 사회성을 높이는 긍정적인 효과가 있었다. 양육민감성이 높을 때 양육스트레스가 낮게 나타난 결과는 양육민감성이 양육스 트레스를 낮춰주는 보호요인이 됨을 의미한다. 즉, 민감한 양 육을 경험한 유아는 자신 및 환경을 긍정적으로 평가하여 반 응하는 행동전략을 발달시키고, 그 과정에서 자신의 정서를 조절하는 힘을 기르게 된다. 이러한 유아의 적응 행동은 어머 니로 하여금 양육의 어려움을 낮추어 양육스트레스가 줄고 이 는 자녀와의 건강한 상호작용 증가로 이어져 다시 유아의 정 서조절능력을 높이는 상보적 순환과정을 추론할 수 있으며, 이러한 추론은 Bowlby (1969)의 내적작동모델 개념을 기초로 한 것이다. 이러한 추론은 양육의 민감성을 높이는 부모교육 프로그램이 양육스트레스 감소에 효과적이며, 이는 궁극적으 로 자녀의 적응능력을 향상시키는 근원적인 접근이 될 수 있 음을 시사한다.

어머니의 양육민감성이 유아의 기질행동 중 부정적 정서성 
은 낮추고 활동성 및 사회성은 높이는 것으로 나타난 본 연구 의 결과는 민감하고 반응적인 양육행동은 기질적으로 예민하 고 부정적 정서성이 높은 자녀의 보호요인으로 작용한다는 견 해(Belsky et al., 1998; Morrell \& Murray, 2003)를 뒷받침한다. 또한 지지적이고 민감한 양육경험을 제공한 중재프로그램이 부정적 정서성이 높은 영아에게 가장 효과적이었다는 연구결 과(Pluess \& Belsky, 2010)와도 그 맥을 같이한다.

유아의 정서조절능력에 대한 양육민감성의 직접 및 간접 영향이 나타난 본 연구의 결과는 Bowlby (1969)의 애착이론을 뒷받침하는 것으로 본다. 온정적이고 반응적인 민감한 양육 은 안정애착을 형성하게 하여 영아 자신과 세상에 대한 신뢰 감 발달을 토대로 정서조절능력을 발달시킨다(H. J. Park et al., 2005). 정서조절능력이 발달되어 가는 과정은 다음과 같다: 긍 정적인 감정 교류 경험은 자녀로 하여금 내적 기쁨을 경험하 게 하고(MacDonald, 1992), 이는 양육자에게 관심을 기울이고 순응하게 하며(Yoo \& Kim, 2017), 그 과정에서 부모가 정서조 절 방법을 직접 가르치거나 모델을 제공하여(Isley et al., 1999) 정서조절능력을 발달시킨다. 본 연구의 결과는 어머니의 양육 민감성이 높을 때 자녀가 자신 및 환경에 대한 조절감을 느끼 며(Bowlby, 2005), 자신의 부정적 정서를 잘 다룰 수 있고(Field et al., 2006), 애착점수가 높을수록 정서조절능력이 높은 것으 로(Hwang \& Bang, 2012; S. A. Kim \& Park, 2009; Seo \& Shim, 2016) 보고한 선행연구결과와도 일치한다.

둘째, 양육민감성이 유아 정서조절능력에 영향을 미치는 경로에서 양육스트레스와 기질 변인이 매개하는지에 대한 평 행다중매개 모델(parallel multiple mediator model) 가설을 검증 한 결과, 양육민감성은 유아의 정서조절능력에 직접 영향을 미칠 뿐 아니라 양육스트레스의 부분매개(partial mediation)를 통해서 간접 영향도 주는 것으로 나타났다. 또한 양육스트레 스는 정서조절능력의 완전매개를 통해 학교준비도에 영향을 미치는 것으로 나타났다. 이러한 결과는 양육스트레스의 부정 적 영향을 밝혀온 선행연구 결과와 일치한다. 어머니의 양육 스트레스는 만 3세 자녀의 부정적 정서표현 증가 및 또래와의 긍정적 상호작용을 감소시키는 등 유아의 정서관련 문제 및 또래관계에 직접 영향을 미칠 뿐 아니라(S. Park \& Park, 2016; J. Yoon, 2017), 자녀와의 상호작용에 부정적인 영향을 미쳐 학 업수행 및 학교생활 적응의 어려움에 간접 영향을 미치는 것 으로 보고되었다(Y. Kim et al., 2019; J. Yoon et al., 2017). 이러 한 간접 영향의 경로를 추론하면, 높은 양육스트레스로 인해 어머니는 자녀의 신체적 정서적 욕구에 민감하게 반응하지 못 하고, 자녀는 욕구충족 부족으로 인해 더 예민해지고 부정적
정서 경험이 증가하면서 상호 간에 부정적 상호작용이 증가하 게 되고, 이로 인해 통제력 부족이나 부정적 또래관계 등 학교 적응 전반에 부정적 영향이 이어질 것으로 본다. 자녀와의 부 적절한 상호작용 및 양육행동을 매개로 한 양육스트레스의 간 접 영향을 밝힌 선행연구(Deater-Deckard, 1998) 역시 이러한 경로추론을 뒷받침한다. 따라서 학령 전 학교준비도를 높이기 위해 양육에 대한 어머니의 스트레스를 줄이는 적극적인 지원 방안을 적극적으로 모색하는 중요하다고 본다.

한편, 정서조절능력에 대한 유아 기질의 매개효과는 나타나 지 않았다. 즉, 유아의 정서조절능력에 영향을 미치는 변인으로 양육민감성 및 양육스트레스를 기질과 함께 분석한 결과, 기질 의 영향력은 유의하지 않은 것으로 나타났다. 이러한 결과는 유 아의 기질에 적합하도록 조율된 민감한 양육을 제공하는 경우 유아의 기질은 정서조절능력에 영향을 미치지 않으며, 학교준 비도에도 그 영향력이 유의미하지 않음을 시사한다. 따라서 유 아의 발달 및 적응능력을 돕기 위한 방안은 환경 변인인 양육민 감성과 양육스트레스에 초점을 맞추고, 기질이란 개인적 변인 은 조화적합성 측면에서 고려하는 것이 바람직하다고 본다.

셋째, 양육민감성은 정서조절능력을 매개하여 유아의 학교 준비도에 영향을 미치는 것으로 나타났다. 또한 양육민간성은 양육스트레스가 정서조절능력을 완전매개(full mediation)하여 학교준비도에 연속다중매개효과를 가지는 것으로 나타났다. 학교준비도에 미치는 정서조절능력의 영향력을 밝힌 본 연구 의 결과는 조절능력과 학습태도 및 과제수행간의 정적인 상 관을 밝힌 선행연구(Blair \& Razza, 2007; Spira \& Fischel, 2005) 결과와 일치한다. 양육민감성이 정서조절능력을 매개로 학교 준비도에 영향을 미치는 것으로 나타난 결과 또한 따뜻하고 합리적인 양육이 긍정적 관계 형성을 통해 인지적 기술 발달 을 포함하여 학교준비도를 높인다는 선행연구(J. A. Lee et al., 2017) 결과와도 일치한다.

정서조절능력은 학습태도 및 수행, 학교생활 적응 등 학교 적응 전반을 예측하는 핵심 요인으로 강조된다(Blair \& Razza, 2007; Murphey \& Burns, 2002). 본 연구에서 양육민감성이 정 서조절능력을 매개로 학교준비도에 영향을 미치는 것으로 나 타난 본 연구의 결과는 민감한 양육이 생애 전반에 걸쳐 발달 및 적응에 일차적 요인으로 작동함을 뒷받침한다. 뇌신경발 달 연구를 근거로 애착의 중요성을 강조한 Tarullo 등(2009)은 다양하고 풍부한 경험과 활동이 조절능력을 관장하는 두뇌영 역 간의 연결망을 구축하고 활성화시켜 조절능력이 발달된다 고 주장하였다. 이는 민감한 양육 경험은 영아의 정서를 안정 시켜 탐색행동을 촉진하며, 이는 다양하고 풍부한 경험으로 
이어지고, 이러한 경험은 조절능력을 관장하는 두뇌영역 간의 교류를 활성화시켜 조절력 발달을 이루어짐을 뜻한다.

이상의 결과를 요약하면, 학교준비도에 영향을 미치는 일 차적인 요인은 양육민감성이며, 정서조절능력을 통한 연속다 중매개효과(serial multiple mediator effect)를 가지는 것으로 나 타났다. 양육민감성은 정서조절능력에 대한 직접 영향 뿐 아 니라 양육스트레스를 통한 부분매개효과가 있었으며, 정서조 절능력를 매개하여 학교준비도에 영향을 미쳤다. 한편 정서조 절능력은 양육스트레스와 학교준비도 간에 영향을 완전매개 하는 것으로 나타났다. 본 연구는 유아의 기질을 양육민감성 및 양육스트레스 변인과 함께 분석했을 때 유아의 정서조절능 력이나 학교준비도에 미치는 영향이 유의미하지 않음을 밝혔 다는 점에서 연구의 의의가 매우 높다고 본다. 또한 양육민감 성이 양육스트레스에 영향을 주며, 이러한 어머니 특성 변인 은 유아의 정서조절능력을 완전 매개하여 학교준비도에 영향 을 미침을 밝힘으로써 유아의 학교준비도를 높이기 위한 지원 방안의 초점을 어머니의 민감한 양육 증진에 두어야 함을 밝 혔다는 점에서 연구의 의의가 있었다고 본다. 학령 전 유아의 학교준비도에 영향을 미치는 주요 변인은 유아의 정서조절능 력이며, 이에 영향을 미치는 주요 변인은 유아의 기질이 아닌 양육의 민감성이나 양육스트레스와 같은 환경적 변인이라는 점을 본 연구는 밝히고 있다. 이러한 결과는 유아기 뿐 아니라 학령기 및 그 이후의 발달전반에 영향을 미치는 중요한 일차 적 환경은 가정, 특히 어머니이며, 민감한 양육을 통해 유아가 어머니와 정서적 친밀감을 형성하고 자신과 세상을 긍정적으 로 평가하는 긍정적인 내적작동모델을 형성하는 것이 그 무엇 보다도 중요함을 재차 강조한다.

본 연구는 유아의 정서조절능력을 측정할 때 다양한 상황 맥락을 고려하지 않고 가정에서의 행동관찰에 근거한 어머니 평가만을 실시하였다는 연구의 제한점이 있다. 유아의 정서조 절능력은 교사, 또래 등 외적 요인에 따른 상황변수에 따라 차 이를 보인다(Moon, 2010)는 점에서 추후 연구를 통해 유아의 정서조절능력을 교실 등 다른 맥락에서도 평가하여 분석하는 것이 필요하다고 본다. 한편 본 연구를 통해 유아의 정서조절 능력 및 학교준비도에 미치는 유아 기질의 영향력은 어머니의 양육민감성 및 양육스트레스 변인과 함께 분석하였을 때 없는 것으로 나타났으나 이를 뒷받침할 선행연구를 찾기가 어려웠 다. 따라서 추후 연구를 통해 어머니의 양육관련 변인 및 유아 기질의 영향력을 동시에 비교분석해 봄으로써 기질의 상대적 영향력을 추가적으로 검증해 보는 것이 매우 의미가 있다고 본다. 본 연구 또한 양육민감성이 발달 및 적응에 일차적 요인
으로 작동함을 뒷받침하였으며, 따라서 추후 연구를 통해 어 머니의 양육민감성을 높이는 부모교육프로그램을 개발하고, 그 효과를 밝히는 다양한 시도가 필요하다고 본다.

\section{Acknowledgements}

This study was supported by the 2019 research grant of Korea Nazarene University.

\section{Conflict of Interest}

No potential conflict of interest relevant to this article was reported.

\section{References}

\section{In English}

Belsky, J., Hsieh, K.-H., \& Crnic, K. (1998). Mothering, fathering, and infant negativity as antecedents of boys' externalizing problems and inhibition at age 3 years: Differential susceptibility to rearing experience? Development and Psychopathology, 10(2), 301-319. doi:10.1017/S095457949800162X

Blair, C., \& Razza, R. P. (2007). Relating effortful control, executive function, and false belief understanding to emerging math and literacy ability in kindergarten. Child Development, 78(2), 647-663. doi:10.1111/j.1467-8624.2007.01019.x

Bornstein, M. H., Tamis-LeMonda, C. S., Pascual, L., Haynes, O. M., Painter, K. M., Galperín, C. Z., \& Pêcheux, M.-G. (1996). Ideas about parenting in Argentina, France, and the United States. International Journal of Behavioral Development, 19(2), 347-367. doi:10.1177/016502549601900207

Bowlby, J. (1969). Attachment and loss: Vol. 1. Attachment. New York: Basic Books.

Bowlby, J. (2005). A secure base. London: Routledge. doi:10.4324/ 9780203440841

Browne, M. W., \& Cudeck, R. (1992). Alternative ways of assessing model fit. Sociological Methods \& Research, 21(2), 230-258. doi:10.1177/0049124192021002005

Bugental, D. B., Olster, D. H., \& Martorell, G. A. (2003). A developmental neuroscience perspective on the dynamics of parenting. In L. Kuczynski (Ed.), Handbook of dynamics in parent-child relations (pp. 25-48). Thousand Oaks, CA: 
Sage Publications.

Byrne, B. M. (2009). Structural equation modeling with AMOS: Basic concepts, applications, and programming (2nd ed.). New York: Routledge.

Deater-Deckard, K. (1998). Parenting stress and child adjustment: Some old hypotheses and new questions. Clinical Psychology: Science and Practice, 5(3), 314-332. doi:10.1111/j.14682850.1998.tb00152.x

Field, T., Diego, M., \& Hernandez-Reif, M. (2006). Prenatal depression effects on the fetus and newborn: A review. Infant Behavior and Development, 29(3), 445-455. doi:10.1016/j. infbeh.2006.03.003

Fonagy, P., \& Target, M. (1997). Attachment and reflective function: Their role in self-organization. Development and Psychopathology, 9(4), 679-700. doi:10.1017/S095457 9497001399

Gaffan, E. A., Martins, C., Healy, S., \& Murray, L. (2010). Early social experience and individual differences in infants' joint attention. Social Development, 19(2), 369-393. doi:10.1111/ j.1467-9507.2008.00533.x

Guralnick, M. J. (1992). A hierarchical model for understanding children's peer-related social competence. In S. L. Odom, S. R. McConnell, \& M. A. McEvoy (Eds.), Social competence of young children with disabilities: Issues and strategies for intervention (pp. 37-64). Baltimore, MD: Paul H. Brookes.

Hair Jr, J. F., Black, W. C., Babin, B. J., \& Anderson, R. E. (2009). Multivariate data analysis (7th ed.). London: Pearson.

Hughes, C. (2011). Changes and challenges in 20 years of research into the development of executive functions. Infant and Child Development, 20(3), 251-271. doi:10.1002/icd.736

Isley, S. L., O’Neil, R., Clatfelter, D., \& Parke, R. D. (1999). Parent and child expressed affect and children's social competence: Modeling direct and indirect pathways. Developmental Psychology, 35(2), 547-560. doi:10.1037/0012-1649.35.2.547

Kam, C.-M., Greenberg, M. T., Bierman, K. L., Coie, J. D., Dodge, K. A., Foster, M. E., . . . Pinderhughes, E. E. (2011). Maternal depressive symptoms and child social preference during the early school years: Mediation by maternal warmth and child emotion regulation. Journal of Abnormal Child Psychology, 39(3), 365-377. doi:10.1007/s10802010-9468-0

Kline, R. B. (2015). Principles and practice of structural equation modeling (4th ed.). New York: The Guilford Press.

Lopez, F. G., \& Brennan, K. A. (2000). Dynamic processes underlying adult attachment organization: Toward an attachment theoretical perspective on the healthy and effective self. Journal of Counseling Psychology, 47(3), 283-300.

MacDonald, K. (1992). Warmth as a developmental construct: An evolutionary analysis. Child Development, 63(4), 753-773. doi:10.1111/j.1467-8624.1992.tb01659.x
Mathiesen, K. S., \& Tambs, K. (1999). The EAS Temperament Questionnaire-Factor structure, age trends, reliability, and stability in a Norwegian sample. Journal of Child Psychology and Psychiatry, 40(3), 431-439. doi:10.1111/1469-7610.00460

Morrell, J., \& Murray, L. (2003). Parenting and the development of conduct disorder and hyperactive symptoms in childhood: A prospective longitudinal study from 2 months to 8 years. Journal of Child Psychology and Psychiatry, 44(4), 489-508. doi:10.1111/1469-7610.t01-1-00139

Murphey, D. A., \& Burns, C. E. (2002). Development of a comprehensive community assessment of school readiness. Early Childhood Research \& Practice, 4(2), 1-14.

Murray, L., \& Cooper, P. J. (1997). Postpartum depression and child development. New York: The Guilford Press.

Pears, K. C., Carpenter, L., Kim, H. K., Peterson, E., \& Fisher, P. A. (2018). The kids in transition to school program. In A. J. Mashburn, J. LoCasale-Crouch, \& K. C. Pears (Eds.), Kindergarten transition and readiness: Prommoting cognitive, social-emotional, and self-regulatory development (pp. 283302). Cham, CH: Springer.

Pluess, M., \& Belsky, J. (2010). Differential susceptibility to parenting and quality child care. Developmental Psychology, 46(2), 379-390. doi:10.1037/a0015203

Rothbart, M. K., Ahadi, S. A., \& Hershey, K. L. (1994). Temperament and social behavior in childhood. MerrillPalmer Quarterly, 40(1), 21-39.

Sobel, M. E. (1982). Asymptotic confidence intervals for indirect effects in structural equation models. Sociological Methodology, 13(1982), 290-312. doi:10.2307/270723

Spira, E. G., \& Fischel, J. E. (2005). The impact of preschool inattention, hyperactivity, and impulsivity on social and academic development: A review. Journal of Child Psychology and Psychiatry, 46(7), 755-773. doi:10.1111/ j.1469-7610.2005.01466.x

Suchman, N. E., \& Luthar, S. S. (2001). The mediating role of parenting stress in methadone-maintained mothers' parenting. Parenting, Science and Practice, 1(4), 285-315.

Tarullo, A. R., Obradović, J., \& Gunnar, M. R. (2009). Self-control and the developing brain. Zero to Three, 29(3), 31-37.

Wallin, D. J. (2007). Attachment in psychotherapy. New York: The Guilford Press.

\section{In Korean}

Bang, S.-Y., \& Hwang, H.-J. (2013). The difference in awareness among parents of preschoolers, parents with school-aged children, child care teachers and elementary school teachers regarding the readiness of children to attend elementary school. Korean Journal of Child Studies, 34(2), 139-160. doi:10.5723/KJCS.2013.34.2.139 
Cho, Y. (2018). Impact of young children's smartphone use and the mediating effects of self-control on school readiness. Korean Journal of Child Studies, 39(4), 13-22. doi:10.5723/ kjcs.2018.39.4.13

Cho, Y. S., \& Lee, K. N. (2010). Effects of adolescent's alienation, depression, family environment and school maladjustment on suicidal ideation. Journal of the Korean Home Economics Association, 48(8), 27-37.

Choi, H.-S., Yoon, H. O., \& Yeon, E. M. (2016). A longitudinal study on the effects of parenting stress and parenting attitude on internalizing and externalizing problem behaviors of preschooler: Focusing on actor and partner effects. Early Childhood Education Research \& Review, 20(2), 495-517.

Hong, K.-P., \& Jo, J.-O. (2015). Impact of proneness to media and internet addiction on problem behaviors in preschoolers. Korean Journal of Early Childhood Education, 35(4), 469491. doi:10.18023/kjece.2015.35.4.021

Hong, S. (2000). The criteria for selecting appropriate fit indices in structural equation modeling and their rationales. Korean Journal of Clinical Psychology, 19(1), 161-177.

Hwang, S.-Y., \& Bang, H.-J. (2012). The effects of attachment and temperament on the emotional and social competence of children. The Korean Journal of the Human Development, 19(3), 147-165.

Jung, D.-H., \& Chi, S.-A. (2006). A case study on the process of children's elementary school adjustment. Early Childhood Education Research \& Review, 10(1), 207-227.

Kim, J. (2013). Internal working model of attachment theory and its therapeutic applications. Korean Journal of Counseling, 14(4), 2485-2507.

Kim, K. H., \& Kang, H. (1997). Development of the parenting stress scale. Journal of the Korean Home Economics Association, 35(5), 141-150.

Kim, S. A., \& Park, S. Y. (2009). Relationships between caregivers' attachment, young children's emotion regulation and aggression: Institutionalized vs. home-reared children. Korean Journal of Child Studies, 30(1), 43-57.

Kim, Y., Kim, K., Choi, Y., \& Yoo, S. (2013). Hanguk adong.cheongsonyeon ingwonsiltae yeongu III: 2013 adong. cheongsonyeoningwonsiltaejosa tonggye [한국 아동. 청소년 인권실태 연구 III : 2013 아동. 청소년인권실태조사 통 계](Report No. 13-R13-2). Retrieved from NYPI website: https://www.nypi.re.kr

Kim, Y., Koo, J. Y., \& Kim, H. K. (2019). Longitudinal effects of mothers' parenting stress on children's academic achievement during the transition to school: The double mediation effects of home environment and school readiness. Korean Journal of Early Childhood Education, 39(3), 191-213. doi:10.18023/kjece.2019.39.3.008

Kwon, M. K. (2011). Parenting stress and related factors of employed and non-employed mothers with infants. Journal of Korean Child Care and Education, 7(2), 19-41.

Lee, H. M., Park, S. Y., \& Seo, S. J. (2008). The effect of maternal parenting style and sensitivity on infant development. Journal of the Korean Home Economics Association, 46(2), 97-111.

Lee, J. A., Park, J. E., Chung, H. M., \& Yi, S. H. (2017). The structural analysis of parents' emotional value of children, parenting behavior, preschoolers' school readiness, and scholastic competence: The actor-partner interdependence model. Korean Journal of Early Childhood Education, 37(4), 453-477. doi:10.18023/kjece.2017.37.4.019

Lee, W. K., Kim, M., \& Yun, K. (2018). Dual earner parents' workfamily conflict, and its associations with warm parenting and early school-aged children's problem behaviors. Korean Journal of Child Studies, 39(3), 141-156. doi:10.5723/ kjcs.2018.39.3.141

Moon, Y.-K. (2010). The effects of maternal emotional availability on preschooler's social skills and problem behaviors: Mediating effects of preschooler's effortful control (Doctorial dissertation). Retrieved from http://www.riss.kr/link?id=T11987431

Park, H. J., Lee, S. H., Choi, H. H., \& Bang, H. J. (2005). The relation of attachment and emotion regulation of infant in the strange situation procedure. The Korean Journal of Developmental Psychology, 18(2), 23-38.

Park, S., \& Park, H. J. (2016). The effects of maternal parenting stress trajectory on affective parenting and socioemotional development of preschooler: Differences between employed and unemployed mothers. Korean Journal of Child Studies, 37(5), 33-52. doi:10.5723/kjcs.2016.37.5.33

Seo, S. O., \& Shim, M. K. (2016). The effect of maternal attitude toward child's emotional expressiveness, young child's attachment stability, and emotional regulation ability on young child's problematic behaviors. Korean Journal of Child Studies, 37(4), 1-15. doi:10.5723/kjcs.2016.37.4.1

Yoo, R. H., \& Kim, S. H. (2017). The relationship between mothers' affective parenting and preschoolers' peer competence: Mediating effects of preschoolers' executive function and emotion regulation. Korean Journal of Child Studies, 38(2), 67-79. doi:10.5723/kjcs.2017.38.2.67

Yoon, J. (2017). The effects of temperament, maternal parenting stress, and maternal parenting behavior on externalizing behavioral problems of preschoolers (Master's thesis). Retrieved from http://www.riss.kr/link?id=T14567912

Yoon, J., Lee, M., \& Lee, Y. (2017). The effect of mother's parenting stress and expectation of child's school adaptation on school readiness as for their child's gender. Korean Journal of Children's Media, 16(1), 131-155. doi:10.21183/ kjcm.2017.03.16.1.131 


\section{KJCS}

\section{ORCID}

Mi Kyung Shim http://orcid.org/0000-0002-7369-4790

Ju Young Woo http://orcid.org/0000-0003-1909-9509
Received August 31, 2019

Revision received September 27, 2019

Accepted October 11, 2019 